\title{
PPA: Programa de Preparação para o Amanhã
}

\author{
José Artur Muniz \\ Universidade Federal do Rio Grande do Norte
}

\begin{abstract}
$\mathrm{N}$ os últimos tempos, um número crescente de organizações vem se preocupando com o processo de aposentadoria dos seus empregados. Compreendendo as expectativas e ansiedades pelas quais passa o indivíduo no período de pré-aposentadoria, essas organizações vêm desenvolvendo Programas de Preparo para Aposentadoria (PPA). Elas entenderam que, além de auxiliarem no cumprimento de suas responsabilidades sociais, tais programas são excelentes ferramentas gerenciais. Ao assumirem essa responsabilidade, fazem um duplo investimento. O primeiro, sobre os empregados que estão se aposentando, que sentem-se valorizados e mantém um bom desempenho. $\mathrm{O}$ segundo, sobre os demais empregados, que observam o cuidado e o respeito que a organização tem pelas pessoas, constatação esta que vem a fortalecer as relações de trabalho.

Para o empregado, o programa é uma oportunidade de obter informações adequadas sobre a aposentadoria; identificar alternativas de atividades pós-aposentadoria; conhecer os recursos que a comunidade dispõe (como associações, programas específicos etc.); e discutir, com pessoas que estão vivenciando um momento semelhante (seus medos, ansiedades, sonhos e aspirações).
\end{abstract}


Mas afinal, como os homens e as mulheres recebem a chegada da aposentadoria? Cheios de planos, ou inseguros e preocupados com uma nova fase em suas vidas?

Em um levantamento feito por Zanelli (1992) junto aos pré-aposentados da Universidade Federal de Santa Catarina (UFSC), alguns depoimentos evidenciam a discrepância no que diz respeito ao significado da aposentadoria para as diferentes pessoas:

"Então você perde a identidade.... - Onde é que tu trabalhas? - Ah, eu não trabalho... Você não tem mais referência"

"A aposentadoria é um presente para quem trabalhou vários anos."

Além dessas posturas, percebemos também aquelas que manifestam situações claras de conflito, ou seja, embora alguns aspectos da aposentadoria sejam atrativos, outros mostram-se aversivos.

A aposentadoria representa, sob o ponto de vista psicológico e social, um momento estressante e de muita expectativa na vida do indivíduo, que suscita reações muito ambivalentes, desde uma sensação de liberdade até um sentimento de exclusão. As mudanças advindas com a aposentadoria requerem uma adaptação, nem sempre atingida pela maioria das pessoas. Caso não haja essa adaptação, os resultados negativos deste novo período podem ser muito sérios, manifestando-se através de depressão, isolamento, dificuldades de relacionamento com a família, etc.

Como afirma Nacarato (1996, p. 279) “...a aposentadoria, que durante a vida profissional podia ser considerada um objetivo, agora pode representar perdas como do status social para a condição de inativo, perda do padrão de vida, além do tédio ocasionado pela dificuldade de administrar o tempo livre".

Os PPAs surgem assim como formas de intervenção, objetivando facilitar a tomada das decisões necessárias ao indivíduo para sua adaptação à nova condição social.

\section{Os PPAs nos diferentes Países}

Nos diversos países onde se desenvolvem os PPAs, vários são os modelos adotados. Todos, porém, parecem seguir o 
padrão norte-americano, adotado desde 1950, que consiste na realização de cursos, em que são discutidas com os participantes, questões tidas como de interesse para pessoas que estão prestes a se aposentar (finanças, saúde, mercado de trabalho etc.)

$\mathrm{Na}$ Espanha, quando da realização do Congresso de Gerontologia, em 1974, definiu-se que seria necessário realizar um trabalho nos últimos 05 anos de atividade profissional dos empregados, visando orientá-los quanto aos problemas que os mesmos encontrarão no período pós-aposentadoria; prepará-los para uma nova atividade; orientá-los quanto ao mercado de trabalho e às questões ligadas à saúde.

No Japão, onde várias empresas desenvolvem estes PPAs, uma delas convida funcionários de 55 anos e suas esposas a participar de um programa de dois dias de duração para discussão do seu futuro. Eles recebem informações sobre aspectos pessoais, financeiros e de saúde. São estimulados a não parar de trabalhar, recebendo prêmio como estímulo à continuidade profissional.

No Brasil, esse trabalho foi iniciado pelo SESC/São Paulo, incluindo o programa desenvolvido, informações sobre a questão do envelhecimento, de recursos sócio-culturais e de serviços da comunidade para os quais os aposentados possam se voltar, a partir da aposentadoria (Magnani, Mendes, Mello, Barbosa \& Bueno, 1993).

\section{A experiência na PETROBRAS/RN}

Como pudemos observar, o modelo que tem norteado a maioria dos Programas de Preparação para Aposentadoria parte do pressuposto de que o aposentando é um idoso, e preocupa-se basicamente em reintroduzi-lo no mercado de trabalho. No Brasil, este último aspecto encontra um terreno fértil, dadas as más condições econômicas da maioria dos aposentados.

Nos últimos quatro a cinco anos, houve uma corrida em direção à aposentadoria, talvez em função das vantagens oferecidas pelas empresas ou pelo receio de uma mudança na 
legislação previdenciária. O fato é que as aposentadorias estão ocorrendo mais precocemente.

Durante o nosso estágio curricular na PETROBRAS/RN, no período de março a novembro de 1996, fomos designados para conduzir o Programa de Preparo para Aposentadoria da empresa, que já existia desde 1992. Até março de 1996, haviam sido realizados quatro cursos, cuja programação enfatizava basicamente informações sobre a questão da reintrodução do aposentado no mercado, relações familiares e questões ligadas à velhice. Os empregados que estavam há pelo menos dois anos da aposentadoria eram o público alvo, juntamente com o cônjuge. A empresa divulgava a realização dos trabalhos e a participação era voluntária.

Feito um levantamento, constatou-se que de janeiro de 1995 a agosto de 1996, apenas um empregado dentre os duzentos que se aposentaram no período, tinha mais de 60 anos (idade considerada como início da velhice pela OMS), enquanto os demais estavam na faixa etária entre 40 a 55 anos. Este foi um dos fatos que motivou o processo de redirecionamento do programa, já que não se poderia considerar este grupo como de pessoas idosas.

Um outro ponto refere-se ao aspecto basicamente informativo da atividade, entendendo-se que a tomada de decisões inerentes ao processo de aposentadoria não pode se apoiar tão somente no intelecto. Afinal, sabe-se que as emoções contam tanto ou mais que as razões, quando se trata de moldar as decisões. Como diz Goleman (1996), as emoções constituem-se essencialmente em impulsos para agir, ou planos instantâneos para lidar com a vida, a nós infundidos pela evolução.

Decididamente, tanto quanto saber o que lhes ocorre, as pessoas necessitam compreender a si próprias diante da nova situação de vida.

Questionou-se também a ênfase na reinserção do aposentado no mercado de trabalho, entendendo ser importante a abertura do indivíduo e seu cônjuge para um mundo de oportunidades que não passam necessariamente pela atividade econômica. 
Finalmente, achamos importante buscar uma resposta para a pergunta: qual o objetivo do trabalho realizado junto ao préaposentado? $\mathrm{O}$ que se pretende promover junto ao mesmo e seu cônjuge? Concluímos que, na realidade, trata-se de despertá-los para a capacidade que cada um possui de definir suas metas, e para as fontes de poder disponíveis (ou a serem promovidas) para sua efetivação, tais como o compromisso, a disciplina, o sistema de apoio social, a orientação interior, a leveza de espírito, o amor e a busca da própria verdade (Gershon \& Straub, 1989). Trata-se, ainda, de levá-los a olhar para sua aposentadoria como um recomeço, um nascimento privilegiado, tornando-se o PPA não apenas um preparo para uma aposentadoria, mas uma preparação para um amanhã, que poderá vir a ser bastante gratificante.

$\mathrm{Na}$ base de tudo, a crença na auto-responsabilidade, na responsabilidade de cada um pelas escolhas de suas vidas (Schultz, 1989); na promoção da auto-estima; e uma atitude positiva diante do mundo.

A partir desses pontos, foi feita uma avaliação dos procedimentos adotados até então, através de discussões com profissionais da área social da empresa, chegando-se a uma redefinição do modelo do PPA.

O novo modelo consiste na realização de um seminário, com quarenta horas de duração, constando de duas partes: a primeira, com duração de oito horas, é basicamente informativa, abordando-se assuntos como saúde, oportunidade de negócios, legislação previdenciária, etc. A segunda, de caráter vivencial, é iniciada por uma atividade visando levar o participante a uma revisão de sua trajetória de vida até ali. Objetivando facilitar a comunicação e percepção interpessoais, são então trabalhadas as habilidades de dar e receberfeedback, consideradas instrumentais para o melhor desenvolvimento do seminário. Auto-percepção é outro aspecto básico trabalhado, visando promover em cada indivíduo um maior conhecimento de si próprio, através de exercícios de dinâmica de grupo e instrumentos de avaliação psicológica.

Os relacionamentos familiares, o afeto e a intimidade, as relações com amigos, o quanto essas relações podem servir 
de base e sustentação para a vida do futuro aposentado são questões bastante enfatizadas na intervenção. Outros aspectos trabalhados: identificar e assumir riscos; o stress e estratégias para lidar com ele; a importância do lazer; e a espiritualidade, entendida não necessariamente em seu aspecto religioso, mas como o propósito superior da existência de cada um. O seminário é encerrado com uma atividade de planejamento de vida.

Em suma, as atividades do seminário estão voltadas para um direcionamento do indivíduo para o futuro, a partir de sua estrutura, origens, crenças, valores, perdas e ganhos em função de mudanças próximas com a chegada da aposentadoria.

A metodologia empregada inclui exposições nas quais o diálogo é estimulado; técnicas de dinâmica de grupo; e jornadas de fantasia, visando estimular o pensamento criativo.

Foram mantidos alguns aspectos dos modelos anteriores existentes, como o público alvo e a forma de recrutamento dos participantes.

\section{Observações finais}

Até dezembro de 1996, dois grupos foram trabalhados dentro do novo modelo. Concluído o segundo grupo, alguns aspectos parecem apresentar uma evolução: os objetivos parecem mais claros e adaptados às características da organização; encontrou-se a abordagem apropriada de modo a garantir que os objetivos sejam trabalhados; as técnicas selecionadas revelaram-se adequadas à promoção do envolvimento dos participantes. Constitui-se, no entanto, em preocupação a continuidade do trabalho, atualmente limitado ao seminário. Parece-nos necessário um acompanhamento cuidadoso dos grupos visando assisti-los no desenvolvimento dos planos elaborados, bem como prover apoio emocional que venha a ser requerido. O estabelecimento e manutenção de sistemas de apoio social, constituídos por pessoas envolvidas nessa vivência comum, são importantes para que os indivíduos possam atravessar o período de transição da forma mais segura e tranquiila possível. Isso reforça mais ainda a necessidade de uma ação no sentido de promover uma continuidade do tra- 
balho iniciado nos respectivos seminários. O acompanhamento, caso devidamente estruturado, deverá ainda oportunizar a ampliação e aprofundamento do conhecimento sobre o tema, bem como o aperfeiçoamento desse tipo de atividade na organização.

\section{Referências}

Gershon, D., \& Straub, G. (1989). Empowerment. New York: Delta.

Goleman, D. (1996). Inteligência Emocional. Rio de Janeiro: Objetiva.

Magnani, L. A. C., Mendes, M. B., Mello, P. M. de, Barbosa, S. A., \& Bueno, K. C. D. (1993). Programas de Preparo para a Aposentadoria (PPA): sua importância e necessidade na sociedade brasileira contemporânea. Curitiba: Faculdade de Direito de Curitiba.

Nacarato, A. E. C. B. (1996). Stress no idoso: efeitos diferenciais da ocupação profissional. In M. E. N. Lipp (Org.), Pesquisas sobre stress no Brasil: Saúde, ocupações e grupos de risco. Campinas: Papirus.

Schultz, W. (1989). Profunda simplicidade. São Paulo: Ágora.

Zanelli, J. C. (1992). Aposentadoria: Percepções dos servidores da Universidade Federal de Santa Catarina. Manuscrito não publicado, Universidade Federal de Santa Catarina, SC.

José Artur Muniz é aluno do curso de Psicologia da Universidade Federal do Rio Grande do Norte. Telefone (084) 983-8463, Fax (084) 235-3503, E-mail: artur@ep-rnce.petrobras.gov.br. Trabalho realizado sob orientação do prof. Paulo Fernandes de Oliveira (Departamento de Psicologia da UFRN). 